Revue des patrimoines

$41 \mid 2019$

Patrimoines gastronomiques. Définitions, typologies et enjeux de conservation

\title{
La protection au titre des monuments historiques des espaces liés à la gastronomie : l'exemple de la Bourgogne
}

Listing places associated with gastronomy, the example of the Burgundy region

\section{Michaël Vottero}

\section{OpenEdition}

\section{Journals}

Édition électronique

URL : http://journals.openedition.org/insitu/25097

DOI : $10.4000 /$ insitu. 25097

ISSN : 1630-7305

Éditeur

Ministère de la Culture

Référence électronique

Michaël Vottero, «La protection au titre des monuments historiques des espaces liés à la

gastronomie : l'exemple de la Bourgogne », In Situ [En ligne], 41 | 2019, mis en ligne le 09 décembre

2019, consulté le 19 décembre 2019. URL : http://journals.openedition.org/insitu/25097 ; DOI :

10.4000/insitu.25097

Ce document a été généré automatiquement le 19 décembre 2019.

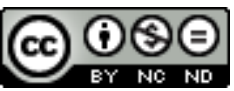

In Situ Revues des patrimoines est mis à disposition selon les termes de la licence Creative Commons Attribution - Pas d'Utilisation Commerciale - Pas de Modification 4.0 International. 


\title{
La protection au titre des
} monuments historiques des espaces liés à la gastronomie : l'exemple de la Bourgogne

\author{
Listing places associated with gastronomy, the example of the Burgundy region
}

\author{
Michaël Vottero
}

Outre les pressoirs, celliers et diverses dépendances viticoles d'abbayes de la région protégés de longue date ${ }^{1}$, la Bourgogne ${ }^{2}$ possède un certain nombre de monuments historiques liés au patrimoine gastronomique. Cette thématique, soutenue par le ministère de la Culture, initiée dans les années 1970 par la protection de boutiques, de halles, de cafés et de restaurants, se poursuit aujourd'hui encore ${ }^{3}$. Face aux mutations commerciales $\mathrm{du} \mathrm{xx}^{\mathrm{e}}$ siècle, cette politique de protections a notamment tenté de préserver les décors et les aménagements de ces commerces de quartier qui jalonnaient les rues des villes bourguignonnes. L'un des premiers constats, lorsque l'on aborde ce corpus, est celui d'une période chronologiquement réduite. En effet, excepté quelques exemples antérieurs à la Révolution française, la plupart des édifices protégés de ce type en Bourgogne datent $\mathrm{du} \mathrm{XIX}^{\mathrm{e}}$ siècle ou du tout début du Xxe siècle. Cette période $\mathrm{a}$ été marquée par une évolution de l'architecture commerciale et des espaces liés à la gastronomie. Les traditionnelles échoppes ont alors cédé la place, en l'espace de quelques années, aux vitrines des boutiques. Les intérieurs sombres ont été remplacés par de larges ouvertures où les marchandises s'exposaient au regard des passants. Les évolutions techniques permettaient désormais de produire des surfaces vitrées de plus en plus importantes. L'hygiénisme ambiant a également participé de la reconstruction de très nombreux marchés couverts. De même, le développement des transports routiers et ferroviaires a fait de la Bourgogne une étape privilégiée entre Paris et le sud de la France. Dès lors, afin d'attirer le client, commerces, cafés et restaurants, se devaient d'orner leurs devantures pour se démarquer de leurs concurrents. Patrimoine fragile, comme nous le verrons, ces aménagements anciens, constamment mis au goût 
du jour dans leurs décors ou reconstruits afin de répondre à de nouveaux besoins, sont aujourd'hui particulièrement rares.

\section{De l'échoppe aux halles métalliques}

2 La Bourgogne conserve quelques rares exemples d'échoppes médiévales ou de l'époque moderne protégées au titre des monuments historiques avec la façade de la maison ou de l'immeuble dont elles occupent le rez-de-chaussée. L'agrandissement des bourgs médiévaux à la Renaissance a contribué à l'apparition de demeures implantées le long des axes passants. Tel est le cas de la maison à colombages du 24 rue Saint-Honoré à Arnay-le-Duc (Côte-d'Or) (fig. 1), inscrite au titre des monuments historiques le 30 avril $1999^{4}$. Situé à proximité de l'entrée sud de la ville, cet édifice du xvI ${ }^{\mathrm{e}}$ siècle, dont on ignore quel commerce il abritait autrefois, a conservé sa disposition d'origine avec boutique, arrière-boutique, couloir et escalier en vis.

Figure 1

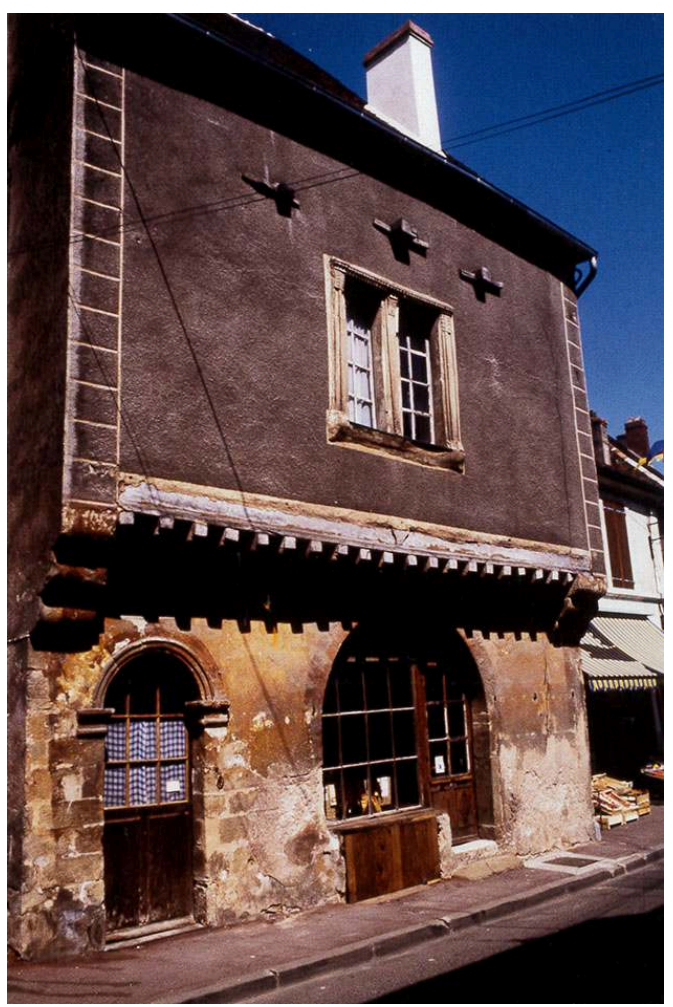

24 rue Saint-Honoré, Arnay-le-Duc (Côte d'Or).

Phot. B. Sonnet, juin 1989. (c) DRAC Bourgogne-Franche-Comté.

3 Ce type d'aménagement se développe et s'amplifie dans les premières années du XIX $\mathrm{x}^{\mathrm{e}}$ siècle comme en témoignent certains arrêtés municipaux, à l'image de celui de la Ville de Dijon du 22 messidor an XIII (11 juillet 1805) pris pour enrayer l'envahissement des rues par les étalages et les enseignes :

De nombreux commerçants entravent la libre circulation des voitures et des gens de pied en se permettant d'anticiper sur la voie commune par des étalages de différentes marchandises qu'ils font au-devant de leur domicile. Plusieurs d'entre eux se sont permis de faire construire des auvents d'une grandeur énorme, d'autres 
ont fait placer au-devant de leur maison des enseignes saillantes et même des enseignes à bras ${ }^{5}$.

4 Les témoignages de commerces antérieurs au $\mathrm{XIX}^{\mathrm{e}}$ siècle n'ont été que très ponctuellement conservés en Bourgogne et protégés, bien souvent, pour en éviter la disparition dans le cadre d'opérations d'urbanisme de la première moitié du $\mathrm{xx}^{\mathrm{e}}$ siècle ${ }^{6}$. Les règlements d'urbanisme permettent aujourd'hui de protéger ce type de façades, avec échoppes et colombages.

5 Avec les échoppes et les boutiques, les marchés sont depuis des siècles l'espace privilégié où s'exposent les aliments, espaces dont le confort et l'hygiène bénéficient d'améliorations au cours du XIX ${ }^{\mathrm{e}}$ siècle. Une campagne d'étude des marchés couverts par la conservation régionale des Monuments historiques a permis de protéger, dès les années 1970, les exemplaires les plus intéressants de la région. L'un des plus remarquables, celui de la ville d'Auxerre (Yonne), avait malheureusement déjà disparu. Il est aujourd'hui connu par les photographies et les cartes postales anciennes (fig. 2). Sa disparition témoigne des destructions nombreuses qui ont touché le patrimoine ancien et particulièrement celui du XIX ${ }^{e}$ siècle dans les années 1960-1970. Ces édifices, liés au marché quotidien ou hebdomadaire, apparaissent comme l'un des éléments marquants de l'urbanisme des centres-villes. Au cours du XIX ${ }^{e}$ siècle, en bien des endroits, le marché est abrité par des halles en dur, d'abord maçonnées, avant d'adopter les technologies nouvelles associant métal et verre. Le développement des halles métalliques va alors de pair avec l'accroissement des échanges et de la population française et joue un rôle central dans l'approvisionnement. L'utilisation du métal permet de dégager les espaces et d'offrir un nombre d'emplacements plus important aux vendeurs. Dès 1853, les halles de Baltard à Paris posent les bases d'une typologie de marchés couverts qui va se diffuser sur l'ensemble du territoire national. Ces halles fermées, par la brique, le verre ou le métal, isolent le marché de la rue et des intempéries. Il devient ainsi un véritable lieu d'échanges et de commerce autour de la nourriture. On trouve également des halles ouvertes, même si elles sont plus rares en Bourgogne. Trois édifices, protégés au titre des monuments historiques, proposent des approches diverses du marché couvert. 
Figure 2

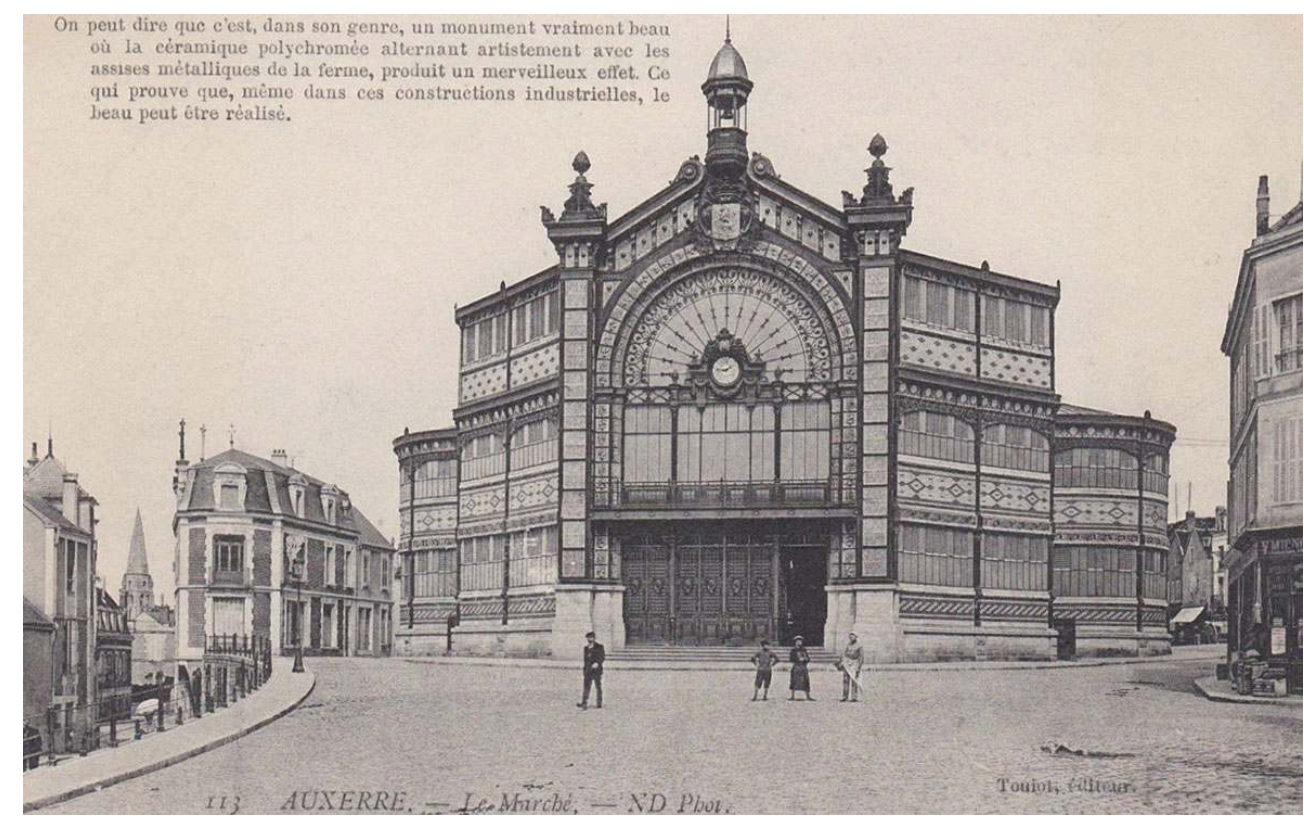

Marché couvert d'Auxerre (Yonne), carte postale ancienne. Coll. part.

Les halles de Dijon (Côte-d'Or), inscrites le 29 octobre $1975^{7}$, qui succèdent au marché installé dans l'ancienne église des Jacobins au lendemain de la Révolution, sont l'archétype même des halles métalliques dérivées de celles de Baltard à Paris. Le projet décidé par la Ville en 1868 est stoppé par la guerre de 1870. L'édifice actuel, conçu par l'architecte Ballard, illustre les nouveaux besoins d'hygiène, d'espace et de sécurité. La construction achevée en 1875 proposait alors 246 emplacements (fig. 3). 
Figure 3

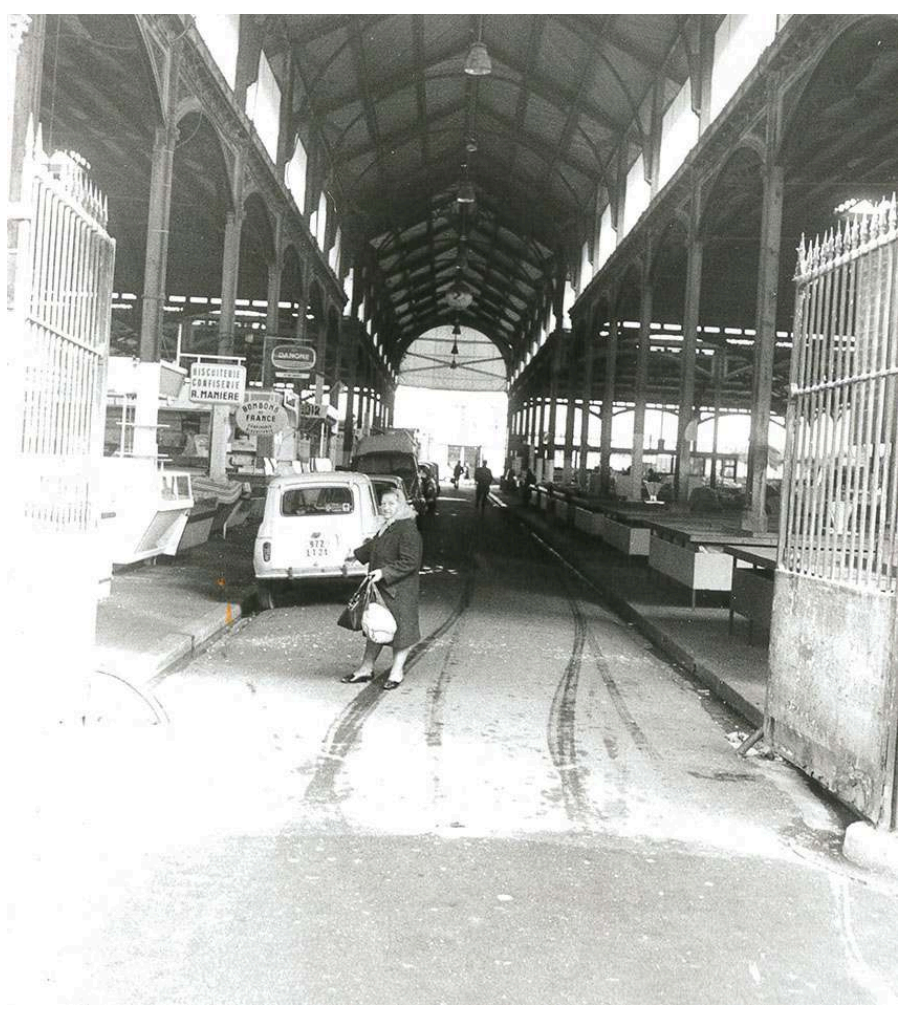

Halles de Dijon (Côte d'Or).

Phot. M. Porcherot, octobre 1974. (C) DRAC Bourgogne-Franche-Comté.

7 Plus petit, le marché couvert de Tonnerre (Yonne), inscrit le 11 juin $1991^{8}$, s'installe sous la mairie, dans l'ancien grenier à sel (fig. 4). Réalisation de Ferdinand Rousseau, architecte d'Auxerre, inauguré en 1904, l'édifice présente une alliance de métal, de verre et de céramiques colorées. Le marché couvert de Sens (Yonne), inscrit le 29 octobre $1975^{\circ}$, est construit en 1882 sur les plans de l'architecte Horace Lefort. Il succède à l'ancien hôtel-Dieu qui l'hébergeait depuis le début du siècle. Sa forme triangulaire lui permet de s'insérer dans le tissu urbain ancien, face à la cathédrale. Ces deux marchés couverts ont été récemment restaurés et ont retrouvé une partie de leur disposition et de leur polychromie d'origine. L'utilisation du verre et du métal, pour ces vastes édifices, se diffuse dans la société et permet de libérer des surfaces importantes en partie basse des immeubles. Les premières vitrines en fonte et verre apparaissent dans les années 1820 en Angleterre et en France. Les colonnes en fonte permettent de reporter la charge de la façade et d'offrir de vastes ouvertures. La devanture qui encadre ces nouvelles vitrines devient alors un véritable enjeu architectural et décoratif, le commerce se met en scène. 
Figure 4

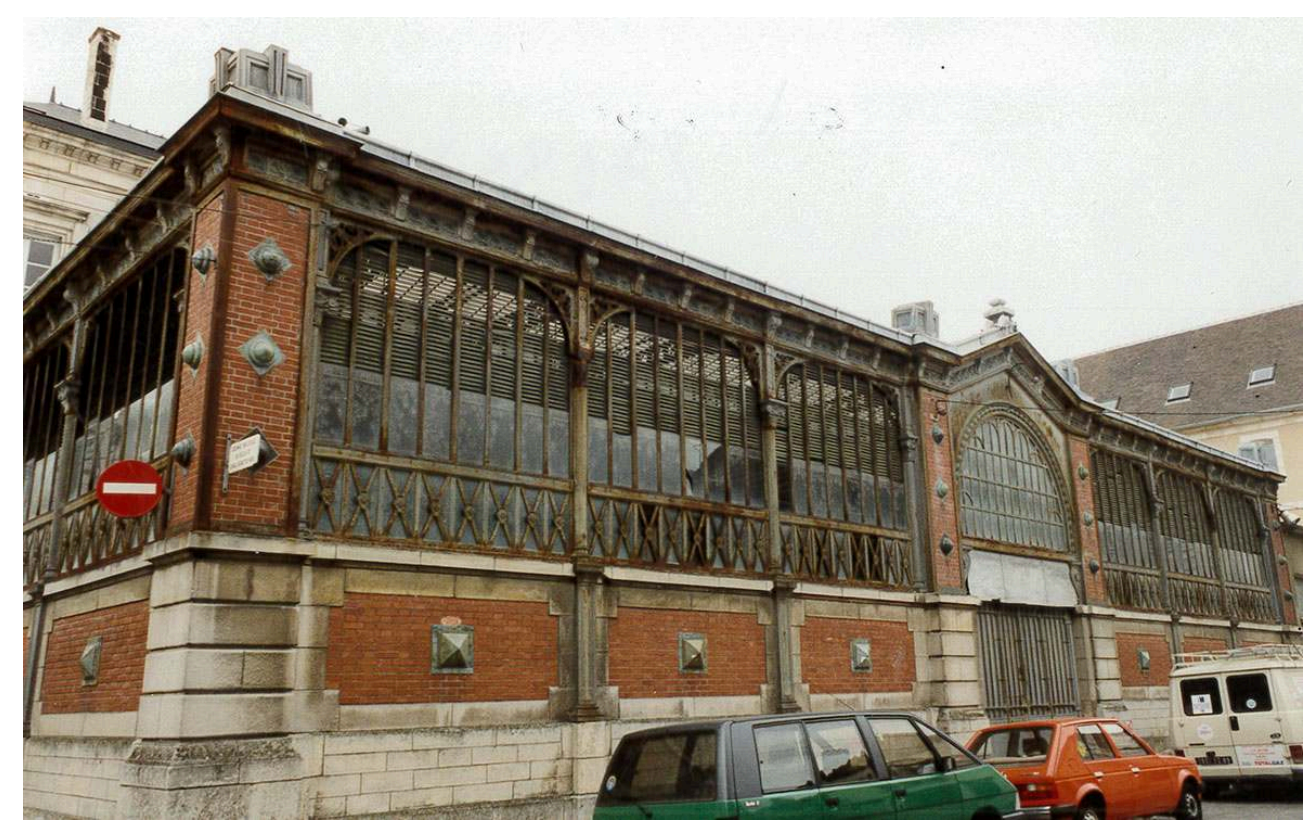

Marché couvert de Tonnerre (Yonne).

Phot. P. de Maulmin, septembre 1990. (c) DRAC Bourgogne-Franche-Comté.

\section{Devantures et boutiques}

Comme l'ont noté Claire Reinharez et Josselyne Chamarat, lors de l'exposition sur les boutiques présentée au musée des Arts et Traditions populaires (Paris) en 1977, le développement de la bourgeoisie, associé à l'hygiénisme et à l'urbanisme galopant des villes, fait une place prépondérante à la gastronomie au XIX siècle. De même que la nourriture évolue, l'ornement des lieux où elle est exposée se transforme ${ }^{10}$. S'il faut attendre les dernières années $d u x_{\text {XIII }}{ }^{e}$ siècle et l'Empire pour voir le phénomène se développer ${ }^{11}$, l'apparition de devantures et de boutiques décorées se développe dans les années 1830. L'alimentation devient un commerce de luxe, comme le rapporte le Journal des peintres en 1835: "Les charcutiers, les pâtissiers et quelques boulangers se distinguent entre toutes les professions par le choix et la beauté des attributs et des décors de tout genre qui ornent la boutique et qui sont pour la plupart exécutés en or sur verre ou en peinture sur toile que l'on place ensuite sous des glaces pour leur faire produire le plus d'effets possibles ${ }^{12}$.» Outre l'aspect décoratif des fixés sous-verre, leur facilité d'entretien explique leur popularité au sein des boutiques. Même chose pour les décors en céramique. Le rôle des devantures est alors d'informer le client sur les produits vendus et d'attirer son regard. Les intérieurs des négoces deviennent parfois de véritables salons. La Bourgogne est toutefois peu marquée par ce type de commerces, plus fréquents dans la capitale et les grandes villes. La région, plutôt rurale, n'en présente que quelques cas isolés.

9 La devanture de la boucherie Saint-Louis à Autun (Saône-et-Loire), 29 rue Guérin, inscrite le 4 août $1995^{13}$, offre ce type de décors de panneaux de marbre noir et de peintures fixées sous-verre, appliqués sur une structure en fonte (fig. 5). 
Figure 5

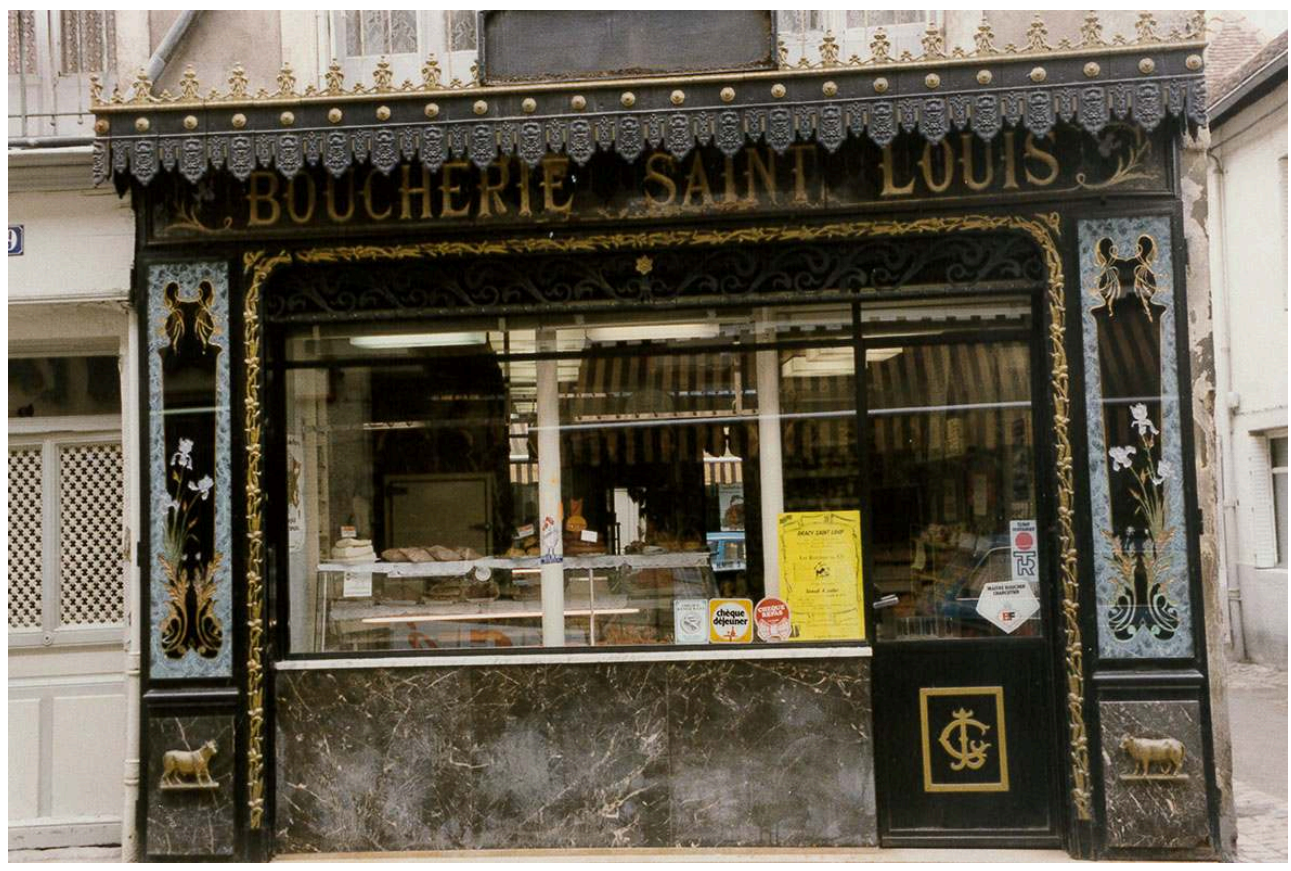

Boucherie Saint-Louis, Autun (Saône-et-Loire).

Phot. B. Sonnet, juin 1987. (C) DRAC Bourgogne-Franche-Comté.

Surmontant l'ensemble, un auvent en zinc protège la devanture. Les motifs floraux des iris sont associés à deux vaches en ronde-bosse dorées qui rappellent la raison sociale du commerce. La devanture de la charcuterie de la grande rue Marchaux à Autun, inscrite le 27 septembre $1995^{14}$, témoigne quant à elle de l'esthétique Art nouveau par ses formes arrondies et les lettres qui composent le bandeau (fig. 6). Toutefois, malgré les lignes coup de fouet du décor, la symétrie des vitrines de part et d'autre de l'entrée sont d'une composition encore classique. Ces devantures sont parfois victimes de vols d'éléments de décor, tel la tête du cheval qui ornait la devanture de la charcuterie, qui a disparu depuis la protection au titre des monuments historiques. 
Figure 6

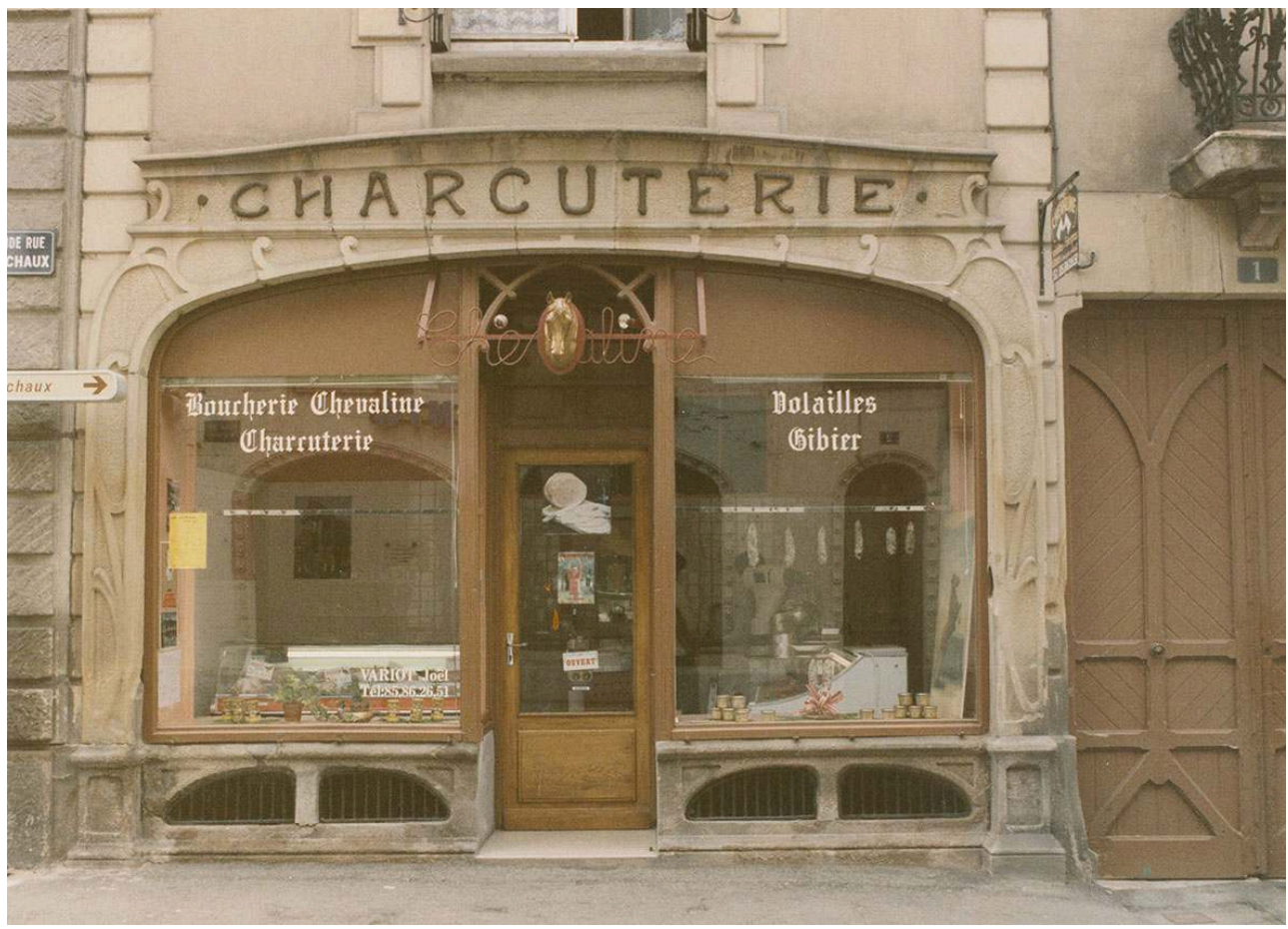

Charcuterie, Grande rue Marchaux, Autun (Saône-et-Loire).

Phot. B. Sonnet, juin 1987. @ DRAC Bourgogne-Franche-Comté.

11 Si seules les devantures de ces deux commerces ont été protégées, c'est le décor intérieur de la boucherie Joseph, 4 rue Guérin à Autun, qui a justifié son inscription au titre des monuments historiques le 22 juin $1995^{15}$. La boutique est ornée d'un lambris et d'un plafond en opaline (fig. $7 \mathbf{a}$ et $\mathbf{b}$ ). L'intérêt des lieux est également qu'ils conservent des éléments de mobilier avec des dessertes et siège en fonte ainsi qu'une magnifique caisse en marbre d'Italie comportant des fontaines à jet d'eau destinées à humidifier l'atmosphère. Sur les murs, les panneaux décorés de paysages sont séparés par des pilastres d'ordre ionique tandis que le plafond est orné d'un décor végétal. S'il n'y a pas de devanture contemporaine avec ce décor, c'est que la fermeture d'origine était une simple grille, comme d'usage pour les boucheries, remplacée par la suite par une vitrine pour protéger des intempéries et satisfaire aux normes d'hygiène. L'aménagement intérieur témoigne de cette volonté, les céramiques ou les fixés sousverre apparaissant comme autant de matériaux nouveaux qui symbolisent alors la modernité du commerce et son caractère hygiénique. 
Figure 7

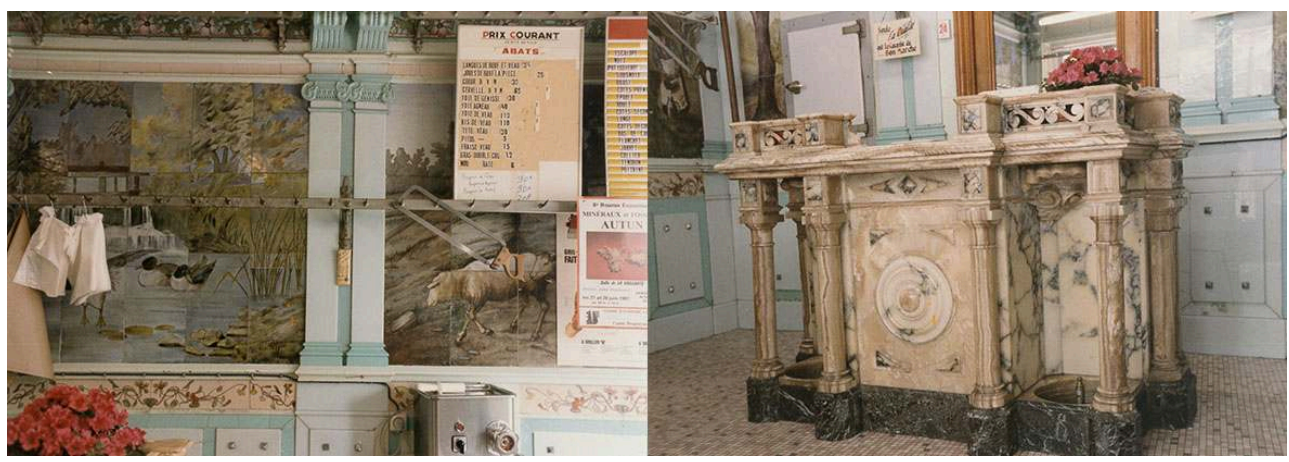

Boucherie Joseph, 4 rue Guérin, Autun (Saône-et-Loire). a. détail du décor en opalines ; b. comptoir en marbre d'Italie.

Phot. B. Sonnet, juin 1987. @ DRAC Bourgogne-Franche-Comté.

La cessation d'activité de la boucherie Joseph, qui n'a pas trouvé de repreneur, n'a heureusement pas conduit à la disparition de ses décors d'opaline, ensemble bien connu des Autunois et reproduit dans des documents de valorisation du patrimoine local. Néanmoins, certains décors, bien que protégés au titre des monuments historiques, sont susceptibles de disparaître lors de travaux de réhabilitation. La charcuterie, installée au 26 de la rue Monge à Dijon, dont la boutique avait été inscrite le 19 juillet $2005^{16}$, a ainsi vu son décor de carreaux d'opaline déposé sans autorisation, et une grande partie de ses éléments cassée. Le décor avait été commandé en 1907 à la manufacture Beyer, de Besançon (fig. 8). Réparti sur les murs et le plafond, il était composé de panneaux maintenus par des vis en tire-fond en laiton. Outre des motifs floraux, les panneaux principaux représentaient des scènes champêtres avec du gibier : faisans, lièvres, chevreuils... Le plafond était orné d'un décor de glycines et d'hirondelles. 
Figure 8

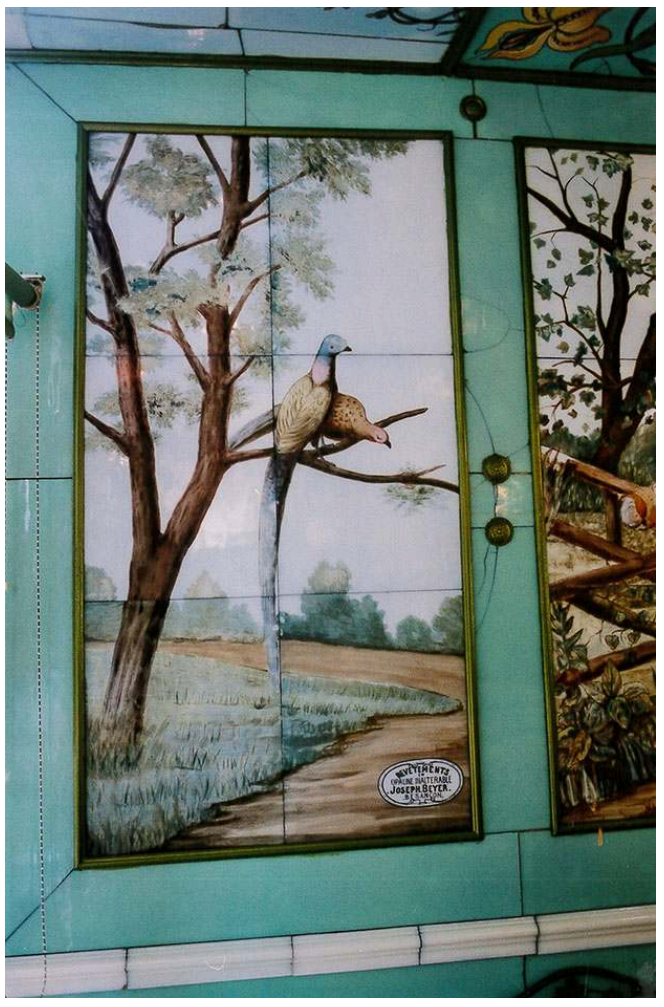

Charcuterie, 26 rue Monge, Dijon (Côte d'Or). $1^{\text {er }}$ panneau gauche. Phot. B. Sonnet, mai 2003. ( DRAC Bourgogne-Franche-Comté.

13 Le $\mathrm{XIX}^{\mathrm{e}}$ siècle voit également apparaître des commerces liés au développement de nouveaux produits tels que les confiseries. Au 25 rue de l'Hôpital à Tonnerre (Yonne), l'ancienne confiserie Thévenin a été protégée en totalité par arrêté du 20 décembre $1991^{17}$. Si la façade sur rue présente une composition traditionnelle avec deux vitrines et un bandeau indiquant la nature du commerce, c'est l'ensemble des décors et objets conservés dans la boutique et le laboratoire qui lui ont valu d'être protégée (fig. 9). 
Figure 9

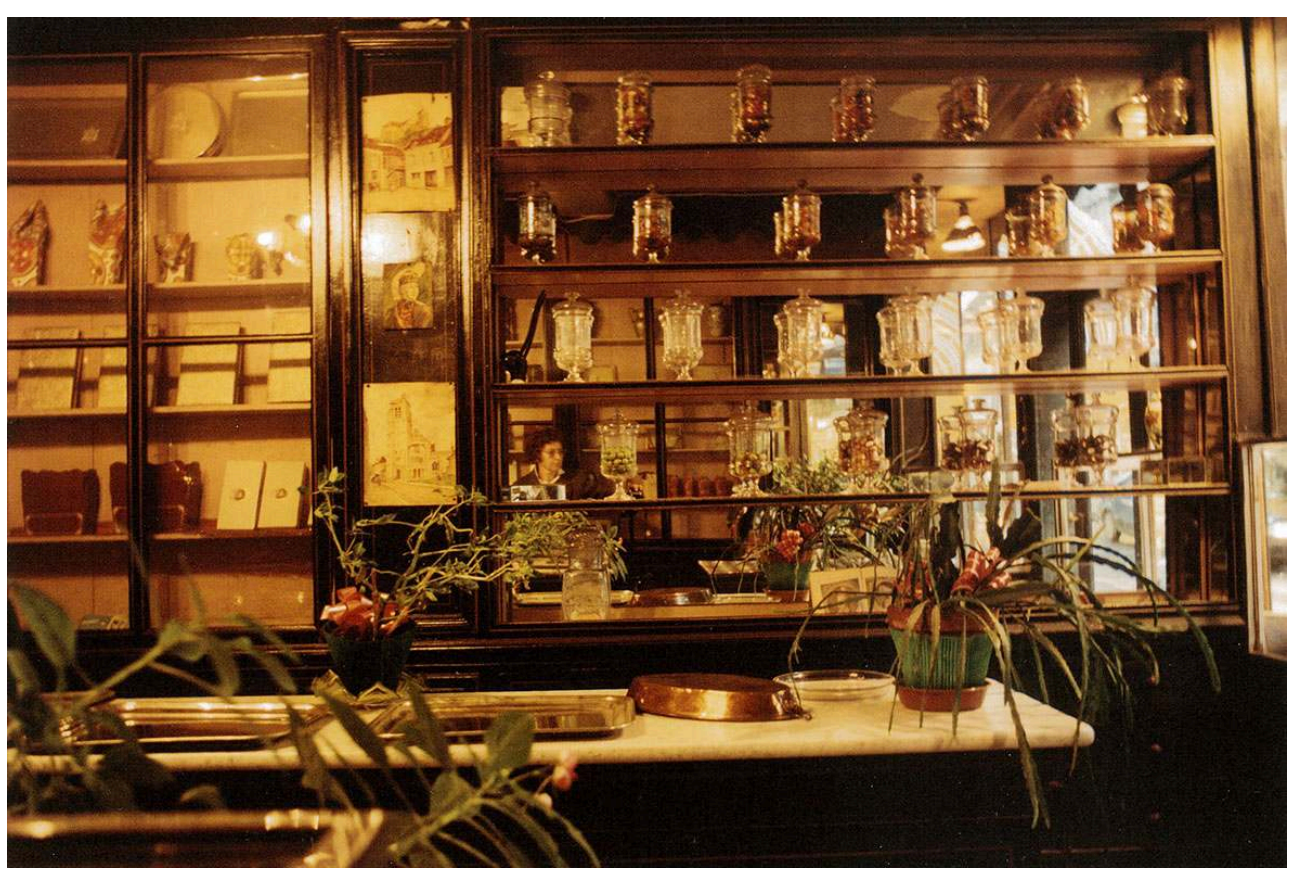

Confiserie Thévenin, Tonnerre (Yonne).

Phot. P. de Maulmin, novembre 1990. @ DRAC Bourgogne-Franche-Comté.

14 Les lieux, achetés par la famille Thévenin en 1900, ont abrité une confiseriechocolaterie jusqu'en 1980. La maison était réputée pour son célèbre bonbon « $\mathrm{Au}$ chevalier d'Éon", une pâte d'amande relevée de liqueur. L'intérieur de la boutique présente un ensemble de vitrines et d'étagères avec leurs bocaux en verre, plats de présentation et boîtes en carton. L'un des comptoirs possède un moulin à moudre le café à usage de confiserie, café utilisé pour parfumer les chocolats, crèmes et pâtisseries. Le laboratoire conserve l'ensemble des ustensiles et des appareils pour la fabrication du chocolat et de la pâtisserie de la première moitié du $\mathrm{xx}^{\mathrm{e}}$ siècle. À l'image de nombreux commerces protégés, les lieux ont été délaissés au décès de Mlle Thévenin, dernière représentante de la famille. Immeuble et boutique ont été rachetés par la Ville de Tonnerre, mais d'importantes fuites d'eau ont provoqué l'altération d'une partie des collections et des appareils du laboratoire. Une visite que nous y avions faite il y a quelques années avec Madeleine Blondel, conservatrice du musée de la Vie bourguignonne à Dijon, a néanmoins permis de découvrir un ensemble encore cohérent et d'une grande richesse, la boutique conservant encore, par exemple, du matériel d'emballage pour les confiseries (papiers divers, rubans, cartons décorés...). Une campagne de protection au titre des monuments historiques de certains objets devrait permettre de préserver les éléments les plus intéressants de cette boutique. La Ville de Tonnerre, après avoir restauré la devanture, ouvre la boutique, depuis quelques années, pour des manifestations culturelles.

Cet exemple peut nous interroger sur la pertinence d'une protection monument historique d'un tel type de patrimoine. Si l'inscription ou le classement permet de préserver une architecture, un décor ou des aménagements intérieurs, ces protections n'ont pas permis, à la différence des musées, de préserver une mémoire ou un savoirfaire. Dans le dossier d'étude constitué pour la protection de la confiserie de Tonnerre, Mlle Thévenin, fille des fondateurs de la boutique, apparaît sur les photographies à 
l'arrière des comptoirs ; pourtant, aucun témoignage sur la vie de la confiserie, le rôle des outils, le choix des emballages pour tel ou tel bonbon ou pâtisserie, n'a été recueilli. Dans les mêmes années, la Ville de Dijon a opté pour une tout autre approche et a racheté des boutiques pour les préserver. En 1978, la fermeture de L'Épicerie modèle, 28 rue de la Liberté, fondée par Léon Fagart, a marqué le début d'une politique qui a conduit à l'aménagement du premier étage du musée de la Vie bourguignonne et à sa rue des commerces $^{18}$. Onze boutiques sont aujourd'hui présentées selon trois approches : la restitution à l'identique, lorsque la devanture, les meubles et les objets sont préservés; la reconstitution, sans la devanture, dans un espace différent du commerce d'origine mais avec une majorité de collections conservées; l'évocation autour de quelques objets. Au lendemain de la fermeture de la boucherie du Bourg en 1984 (fig. 10), le musée a entrepris une véritable campagne de collecte de la mémoire auprès de Mme Noirot, ancienne propriétaire. Ce travail de recueil de mémoire permet, aujourd'hui encore, de faire vivre et d'animer ces collections. Les protections récentes au titre des monuments historiques de boutiques suivent une approche similaire en documentant les lieux par un travail en archives et par des entretiens avec les propriétaires pour étoffer le dossier de protection.

Figure 10

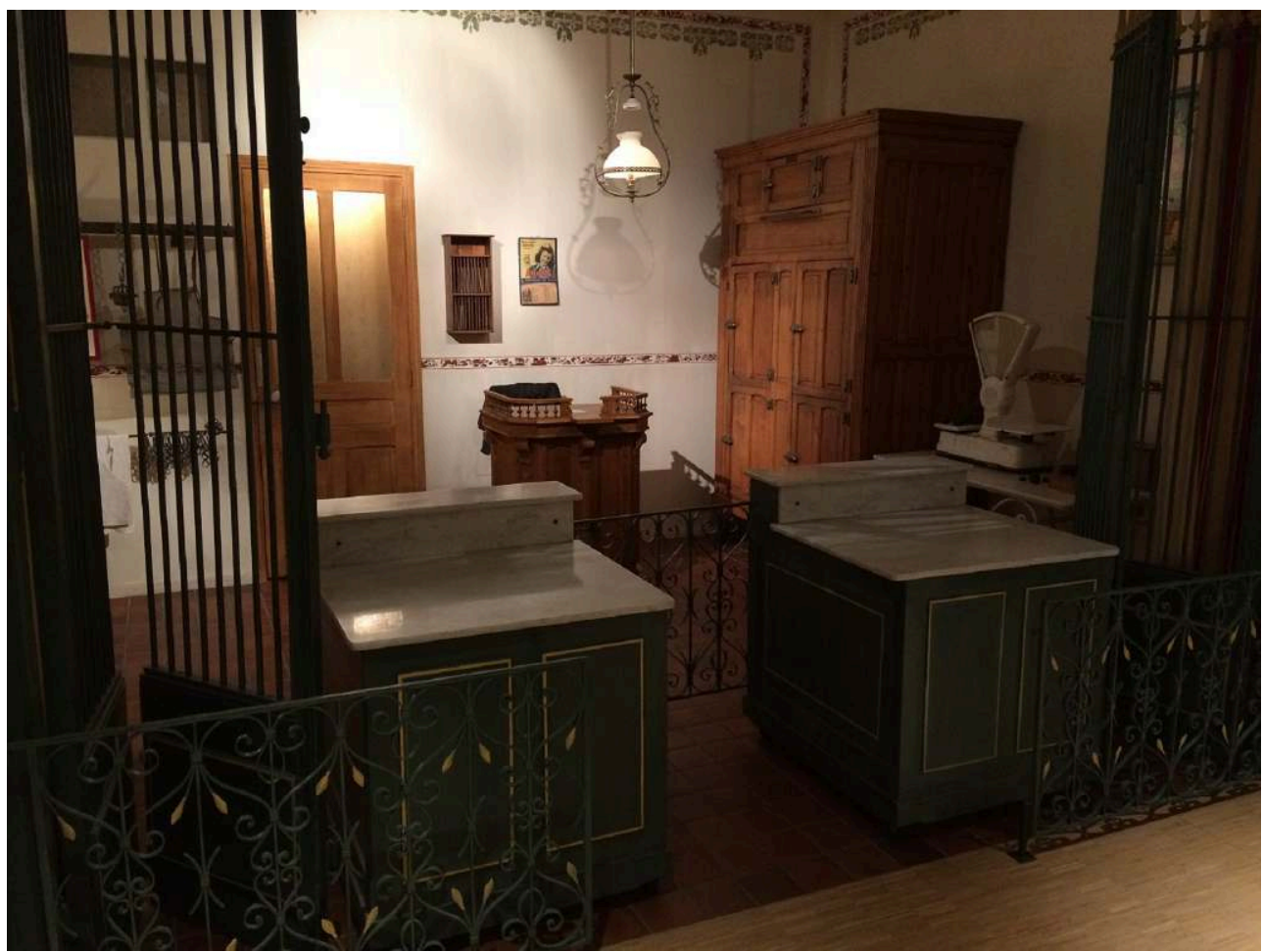

La Boucherie du Bourg au musée de la Vie Bourguignonne, Dijon (Côte d'Or).

Phot. M. Vottero, septembre 2019. (c) M. Vottero.

La boutique Au Négus, à Nevers, a fait l'objet de l'une des plus récentes protections de ce type, avec une inscription du 16 février $2015^{19}$. L'histoire de ce commerce situé 96 rue François-Mitterrand débute vers 1885, avec l'installation à cette adresse d'Edmond Randier, confiseur-glacier-pâtissier. Le bonbon Négus, un caramel au chocolat ou au café sous un enrobage croquant, est probablement créé à la fin de l'année 1900 ou au début de 1901 et baptisé en l'honneur de l'empereur d'Abyssinie Ménélik II (1844-1913), 
couronné Négusse Negest (Roi des rois) d'Éthiopie le 3 novembre 1889 et surnommé le Négus à l'occasion de sa visite officielle en France pour l'Exposition universelle de 1900. La marque « Négus » est déposée en 1902 et ce nouveau bonbon reçoit la même année la médaille d'or de Nevers. Si l'extérieur de la boutique est plutôt classique, l'intérieur présente un décor néomauresque (fig. 11). Il se compose de carreaux de faïence, de carreaux de ciment, de mosaïques, de vitraux colorés et d'un plafond peint rappelant les ornements orientaux. Les murs sont pourvus d'étagères, en alternance avec de grands miroirs, sur lambris d'appui et boiseries architecturées. Outre son décor, la boutique conserve du mobilier, dont une imposante caisse centrale, flanquée de deux présentoirs latéraux. Il est enfin intéressant de noter que la boutique a été protégée " au titre du patrimoine gastronomique», comme le mentionne son arrêté d'inscription. Cette volonté d'attirer les clients par une devanture originale ou un intérieur spectaculaire se retrouve dans le domaine des cafés et restaurants qui se développent dans les mêmes années.

Figure 11

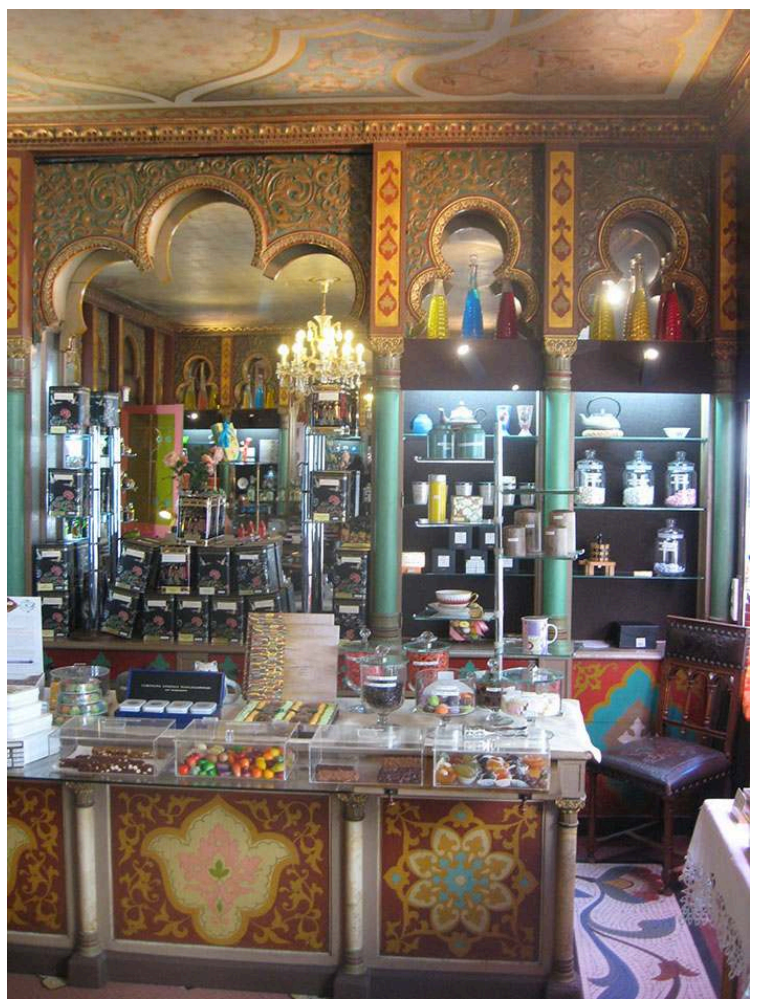

Au Négus, Nevers (Nièvre).

Phot. M. Vottero, février 2012. (c) DRAC Bourgogne-Franche-Comté.

\section{Gastronomie et tourisme}

17 Très fréquentée, la route nationale $n^{\circ} 6$, route du Sud et des vacances, fut longtemps le seul axe reliant Paris à Lyon. Elle était jalonnée de nombreux restaurants et cafés. La commune de Rouvray (Côte-d'Or) se développe et en devient l'une des villes étapes avant la création de l'autoroute A6. Le Café du soleil, dont la façade est inscrite depuis le 27 mars $1986^{20}$, présente une devanture composée de deux vitrines, posées sur un 
soubassement composé de carreaux de faïence à faux-bossages, entourées de briques émaillées vert (fig. 12). Les côtés sont décorés de panneaux de céramique aux motifs floraux stylisés réalisés par la célèbre maison Émile Müller de Paris, qui apportent une touche 1900 à l'ensemble. Bien en vue, à l'angle de la grande rue et de la cour de l'hôtel, la devanture était faite pour attirer les regards. Comme on peut encore le voir, la polychromie y contribue largement. Aux faïences s'ajoutent des verres gravés à l'acide, ornés de décors d'arabesques et de grappes de raisin.

Figure 12

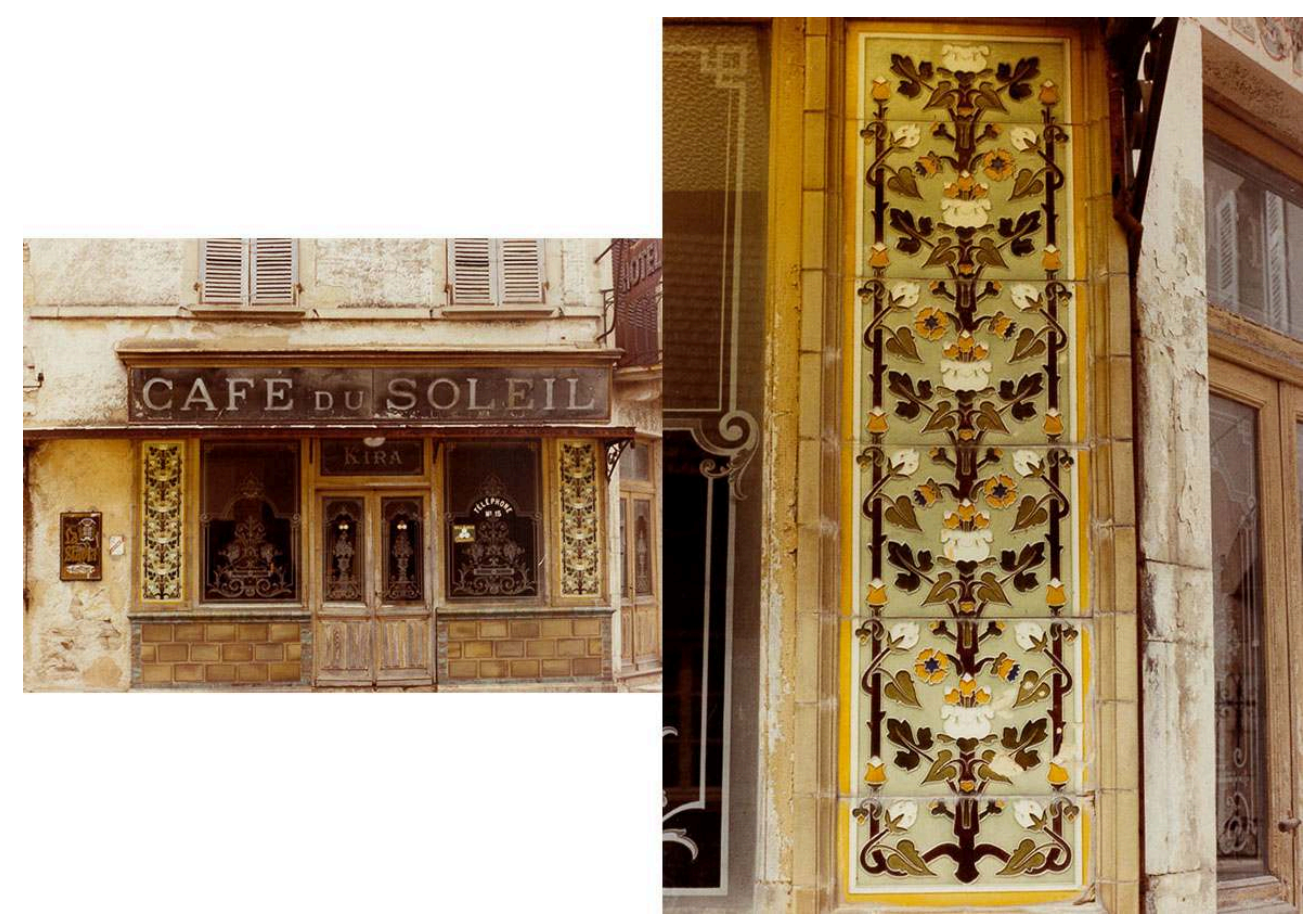

Café du Soleil, Rouvray (Yonne), façade et détail des céramiques. a. devanture ; b. détail des céramiques.

Phot. B. Sonnet, août 1982. @ DRAC Bourgogne-Franche-Comté.

La façade du Café des chiens blancs à Laignes (Côte-d'Or) est inscrite depuis le 19 janvier 1995. Situé sur la place du village, le café ne conserve plus que sa façade en bois peint, datée vers 1850, composée de huit baies en arc brisé à réseau de lancettes et cœur, la salle intérieure ayant perdu l'ensemble de ses décors (fig. 13). 
Figure 13

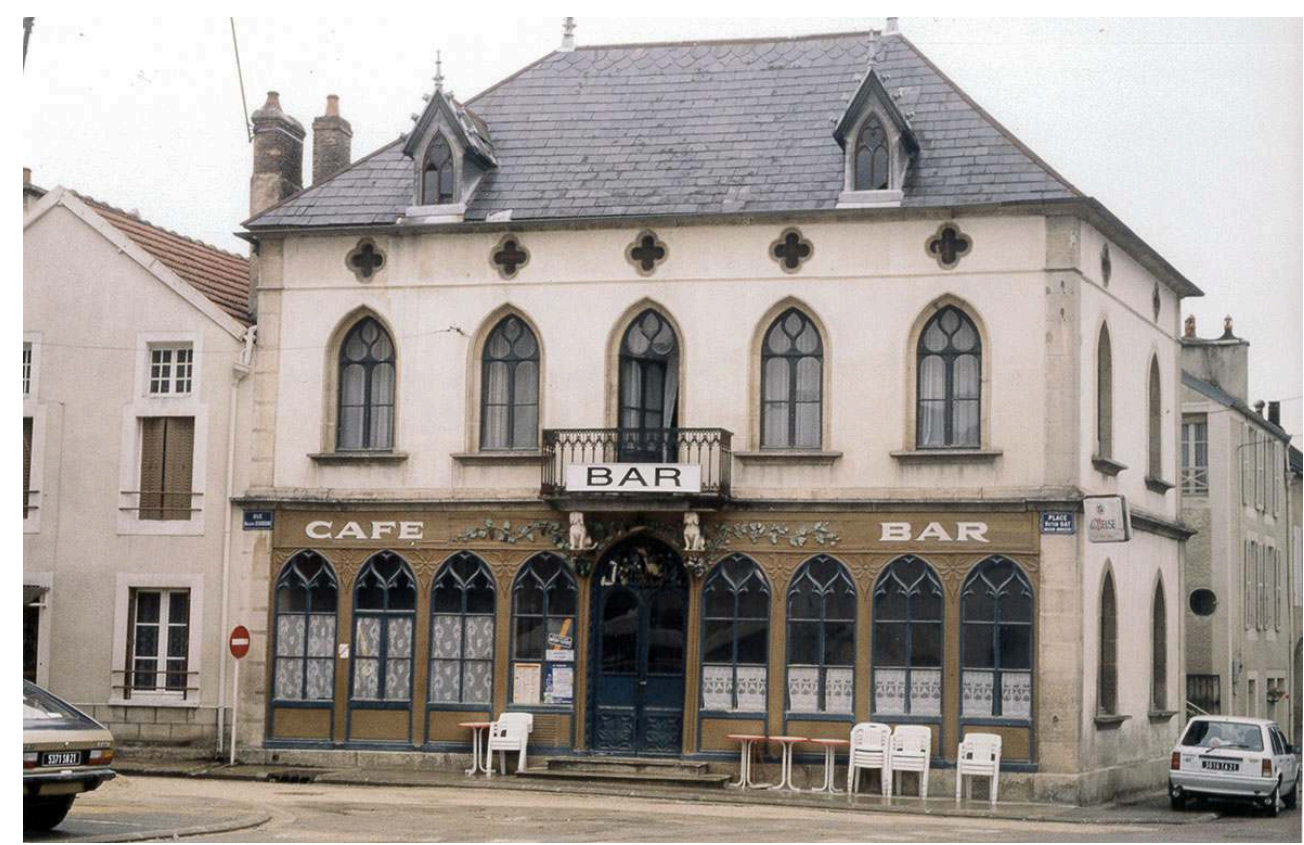

Café des chiens blancs, Laignes (Côte-d'Or).

Phot. B. Sonnet, juin 1991. (c) DRAC Bourgogne-Franche-Comté.

La porte centrale présente un relief sculpté en ronde-bosse évoquant les saisons : putti portant des pampres, une gerbe de blé, une guirlande de fleurs ou un manteau. La porte-fenêtre du premier étage ouvre sur un balcon supporté par deux consoles ornées de chiens blancs, qui donnent leur nom au café, assis sur des culots décorés de branches de vigne ou de rosier. Inscrit la même année, le 22 juin 1995, le Café de la Bourse à Autunn $^{21}$, sur l'avenue du Général-de-Gaulle, ancienne avenue de la Gare, ne possède pas de façade originale ; son intérêt réside dans les décors intérieurs Art nouveau (fig. 14). Les riches encadrements des miroirs, ornés de feuillages, d'iris et de visages féminins, décorent les murs de la salle. Le décor d'iris se poursuit sur les corniches et la rosace du plafond. 


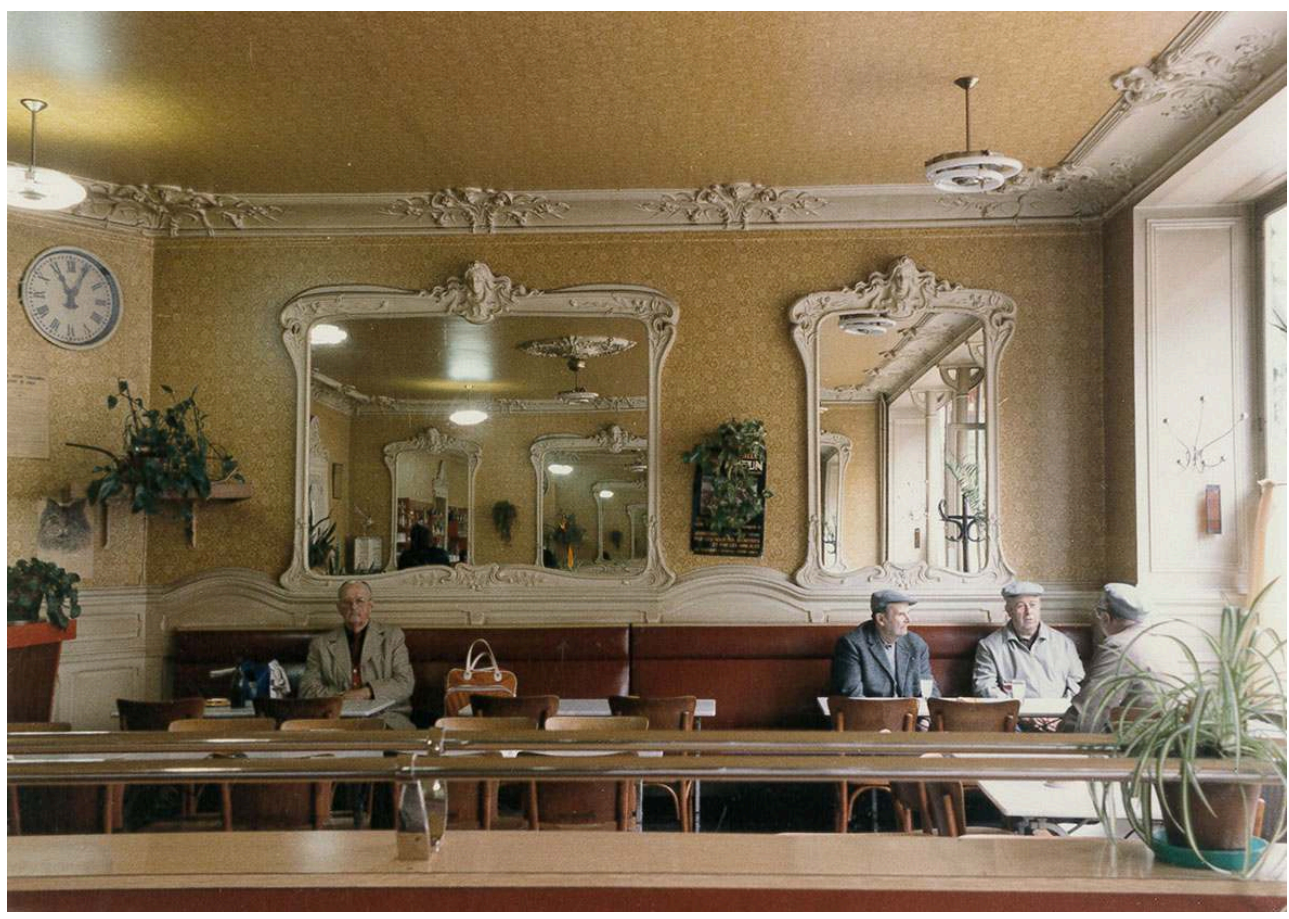

Café de la Bourse, Autun (Saône-et-Loire).

Phot. B. Sonnet, juin 1987. ( ) DRAC Bourgogne-Franche-Comté.

Le développement du train ne remet pas en cause l'existence des établissements ponctuant la route, le $\mathrm{XIX}^{\mathrm{e}}$ siècle voit même de nombreuses enseignes apparaître, comme l'hôtel de la Côte d'Or à Saulieu, dont la salle de restaurant est inscrite depuis le 4 octobre $2010^{22}$. Au début du $\mathrm{xx}^{\mathrm{e}}$ siècle, la ville devient une halte obligée pour les vedettes ou les voyageurs partant pour le sud de la France. C'est sans doute lors de l'achat de l'établissement, au début du siècle, par Paul Budin et son épouse que la salle de restaurant fut aménagée. Ils restaurent les lieux et dotent l'hôtel de tout le confort moderne avec chauffage central et salles de bains. Dès la création des étoiles de bonne table par le Guide Michelin en 1926, La Côte d'Or reçoit une étoile. En 1930, les lieux sont repris par Alexandre Dumaine. La seconde étoile arrive en 1931, puis la troisième en 1935. La réputation de Dumaine est alors à son apogée. On le qualifie de « cuisinier des rois ou roi des cuisiniers" ou encore d'«Alexandre le Magnifique ». Outre le roi d'Espagne Alphonse XIII, figurent dans le livre d'or les noms du prince Rainier, de Sacha Guitry, d'Orson Welles, de Vivien Leigh, d'Édith Piaf, de Salvador Dali... Repris par Claude Verger en 1964, la gérance est confiée à Bernard Loiseau en 1975. Dès 1981, celui-ci obtient trois étoiles et rachète le restaurant en 1982. Tout en gardant la salle située à l'angle des deux rues, hommage à son illustre prédécesseur, il transforme l'établissement en profondeur. Depuis la disparition de Bernard Loiseau en 2003, son épouse, Dominique Loiseau, assure la continuité de l'établissement. Outre le décor préservé (fig. 15), on peut y voir le portrait d'Alexandre Dumaine, daté du 12 novembre 1937, des menus et diverses photographies. Les lambris d'appui sont recouverts d'une peinture faux-bois et la partie supérieure ornée de faux panneaux d'arabesques sur fond pastel. Le plafond à solives est peint de motifs au pochoir. L'élément remarquable en est le carrelage du sol, composition des ateliers céramiques Perrusson, d'Écuisses (Saône-et-Loire), figurant dans le catalogue de 1903. 
Figure 15

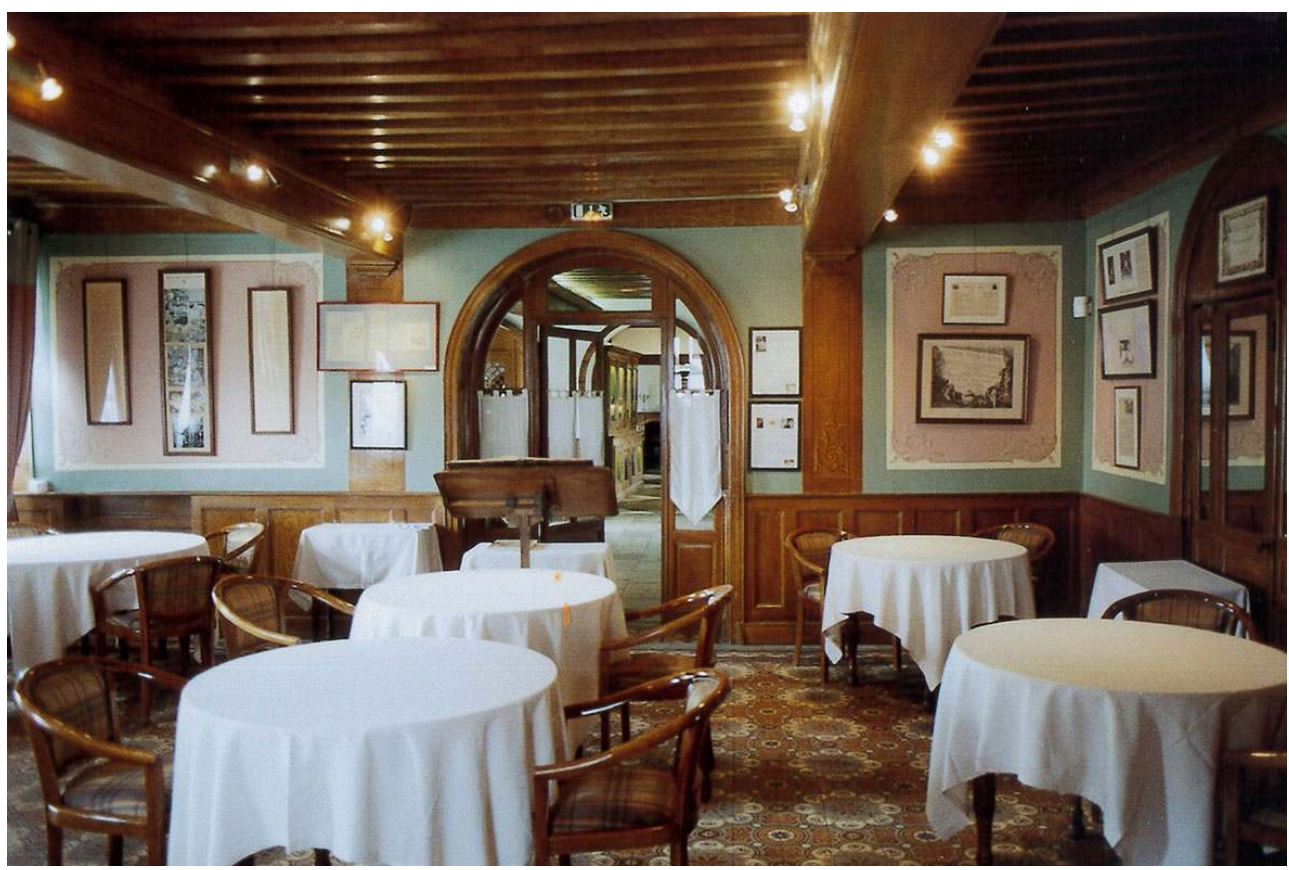

La Côte d'Or, Saulieu (Côte-d'Or)

Phot. B. Sonnet, septembre 2009. (C) DRAC Bourgogne-Franche-Comté.

Moins connu que la célèbre institution de Saulieu, le Café du Rocher à Marsannay-la-Côte (Côte-d'Or) a été classé, pour ses décors, le 10 mars 201723. Dans le cadre d'une thématique sur le patrimoine des Climats de Bourgogne (protégés au titre de l'Unesco), les lieux ont été repérés pour la qualité du décor intérieur d'un café-restaurant de la première moitié du XIX ${ }^{\mathrm{e}}$ siècle ${ }^{24}$. Créé vers 1830 , le Café $d u$ Rocher est toujours en activité. Si la façade est ornée de rocailles, ce sont les trois salles qui présentent un riche décor de rochers ornés de verres colorés, de coquillages et de personnages (fig. 16). Des meubles sont insérés dans le décor, tel un buffet avec ses tiroirs ou un bar. La salle principale, outre ce décor minéral, est ornée de peintures de paysages qui pourraient évoquer les campagnes napoléoniennes. À l'origine, le café se nommait en effet Relais $d u$ soldat de Napoléon. Une partie du décor peint pourrait être attribuée à Louis-Alexandre Gaitet, petit-fils du fondateur du café, peintre et conservateur adjoint au musée des Beaux-Arts de Dijon. 
Figure 16

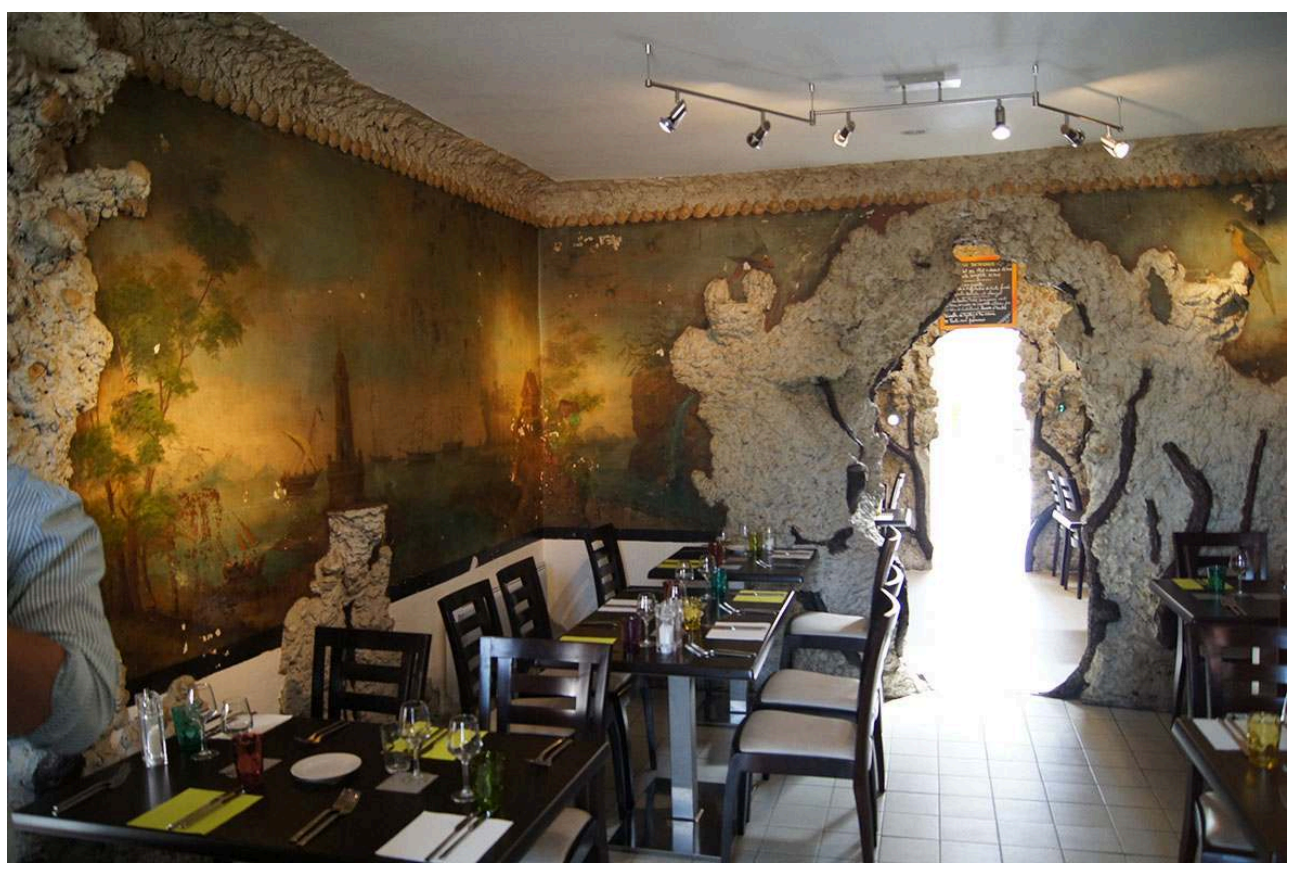

Le Café du Rocher, Marsannay-la-Côte (Côte-d'Or).

Phot. S. Loppinet-Méo, août 2013. @ DRAC Bourgogne-Franche-Comté

Le repérage de commerces anciens, en vue de protections au titre des monuments historiques, se poursuit aujourd'hui. Après les boutiques du tournant des $\mathrm{xIX}^{\mathrm{e}}$ et $\mathrm{xx}^{\mathrm{e}}$ siècles, qui sont les plus protégées, l'intérêt se porte maintenant vers des boutiques des années 1930-1950. Certains exemples de style Art déco, ornés de mosaïques aux motifs stylisés, font l'objet d'études, comme les devantures décorées par le carreleur Luigi d'Andrea dans le département de la Nièvre.

En conclusion, nous pouvons constater que la protection au titre des monuments historiques des boutiques de Bourgogne, si elle a préservé des devantures ou des décors intérieurs, n'a bien souvent pas permis de conserver les commerces qui étaient en activité lors de l'instruction du dossier de protection. Ainsi, sur les neuf boutiques ou cafés protégés, seuls trois sont encore en activité. Le phénomène peut s'expliquer par un changement des modes de consommation qui conduit à la disparition des commerces alimentaires au profit des grandes surfaces ou d'autres types de marchandises. Ces changements de destination posent la question, comme pour la charcuterie de la rue Monge à Dijon, de la reconversion des lieux en présence de décors dont la signification n'est plus en adéquation avec l'activité actuelle ou le produit proposé. En effet, comme l'ont étudié Anne-Cécile Mermet et Maria Gravari-Barbas, le temps long de la protection monument historique se heurte bien souvent au temps plus rapide du commerce, à la demande régulière de modifications des devantures et des intérieurs ${ }^{25}$. Ces décors peuvent toutefois apparaître comme une plus-value pour les nouveaux commerces, certaines enseignes jouant sur l'originalité et la qualité patrimoniale de leurs boutiques. La restauration récente des marchés couverts de Tonnerre et de Sens illustrent l'un des aspects positifs de la protection au titre des monuments historiques, la remise en état d'ensembles dénaturés au fil des ans et la restitution d'éléments de décors disparus qu'un projet de rénovation n'aurait sans doute pas comprises. Espérons que les restaurations de boutiques, de cafés ou de 
restaurants de la région permettront de leur redonner tout leur lustre et de les voir rouvrir avec une destination liée, comme à l'origine, au domaine de la gastronomie.

\section{NOTES}

1. - LOPPINET-MÉO, Sophie, VOTTERO, Michaël. «Les protections au titre des monuments historiques de la Bourgogne viticole (1920-2015)». Dans WOLIKOW, Serge et JACQUET, Olivier (dir.). Bourgogne(s) viticole(s), enjeux et perspectives historiques d'un territoire. Dijon: Éditions universitaires de Dijon, 2018, p. 163-168.

2. - Bien que la DRAC s'occupe, depuis la fusion des régions, des anciennes régions Bourgogne et Franche-Comté, notre article se propose de n'aborder que les monuments protégés en Bourgogne avant cette fusion, et bien que la CRMH de Franche-Comté ait également abordé cette thématique.

3. - Sauf mention contraire, les informations concernant les édifices protégés au titre des monuments historiques proviennent des dossiers de protection.

4. - Voir dans la base Mérimée: http://www2.culture.gouv.fr/public/mistral/merimee_fr? ACTION=RETROUVER\&FIELD_1=cmer1\&VALUE_1=arnay\%20le\%20duc\&FIELD_2=cmer4\&VALUE_2=\&FIELD_3=cmer5\&VALUE_3=\&FIELD 5. - Cité par BLONDEL, Madeleine. « De l'enseigne en boutique, à la boutique comme enseigne ». Dans Dijon clair-obscur. Cat. exp., Dijon, musée de la Vie bourguignonne-Perrin de Puycousin. Dijon : musée de la Vie bourguignonne-Perrin de Puycousin, 1994, p. 22.

6. - Nous pouvons citer notamment la Maison du 9 rue des Cochons-de-lait à Chalon-sur-Saône (Saône-et-Loire), inscrite le 9 décembre 1929 (détruite en mars 1941, boutique du rez-de-chaussée conservée pour un remontage non réalisé. L'immeuble a été radié de l'inscription au titre des monuments historiques le 23 janvier 2017) ; les immeubles, 6 et 8 rue de la Préfecture à Dijon, inscrits le 24 juin 1943 ; l'immeuble, 63 rue de la République à Tournus, boutique du rez-dechaussée, façades et toitures inscrites le 27 septembre 1948; la maison, 2 rue des Hôtelleries à La Charité-sur-Loire, inscrite le 22 juin 1956.

7. - Voir dans la base Mérimée: http://www2.culture.gouv.fr/public/mistral/merimee_fr? ACTION=RETROUVER\&FIELD_1=cmer1\&VALUE_1=dijon\&FIELD_2=cmer4\&VALUE_2=\&FIELD_3=cmer5\&VALUE_3=\&FIELD_4=AUTR\&VAL 8. - Voir dans la base Mérimée: http://www2.culture.gouv.fr/public/mistral/merimee_fr? ACTION=RETROUVER\&FIELD_1=cmer1\&VALUE_1=tonnerre\&FIELD_2=cmer4\&VALUE_2=\&FIELD_3=cmer5\&VALUE_3=\&FIELD_4=AUTR\& 9. - Voir dans la base Mérimée: http://www2.culture.gouv.fr/public/mistral/merimee_fr? ACTION=RETROUVER\&FIELD_1=cmer1\&VALUE_1=sens\&FIELD_2=cmer4\&VALUE_2=\&FIELD_3=cmer5\&VALUE_3=\&FIELD_4=AUTR\&VALL 10. - REINHAREZ, Claudine et CHAMARAT, Josselyne. Paris, boutiques d'hier. Cat. exp., Paris, musée des Arts et Traditions populaires, 1977. Paris : RMN, 1977 ; voir également l'ouvrage publié à l'occasion de l'exposition : Eaed. Boutiques du temps passé. Décors peints des boulangeries, charcuteries et crémeries. Paris : Les Presses de la connaissance, 1977.

11. - DESCAT, Sophie. «La boutique magnifiée. Commerce de détail et embellissement à Paris et à Londres dans la seconde moitié du XVIII siècle ». Société française d'histoire urbaine, 2002/2, $\mathrm{n}^{\circ} 6$, p.69-86. Voir le site: https://www.cairn.info/revue-histoire-urbaine-2002-2-page-69.htm\# [consulté le 17/10/2019].

12. - REINHAREZ, C. et CHAMARAT, J. Op. cit., cité p. 27.

13. - Voir dans la base Mérimée: http://www2.culture.gouv.fr/public/mistral/merimee_fr?

ACTION=RETROUVER\&FIELD_1=cmer1\&VALUE_1=autun\&FIELD_2=cmer4\&VALUE_2=\&FIELD_3=cmer5\&VALUE_3=\&FIELD_4=AUTR\&VA 
14. - Voir dans la base Mérimée: http://www2.culture.gouv.fr/public/mistral/merimee_fr? ACTION=RETROUVER\&FIELD_1=cmer1\&VALUE_1=autun\&FIELD_2=cmer4\&VALUE_2=\&FIELD_3=cmer5\&VALUE_3=\&FIELD_4=AUTR\&VA 15. - Voir dans la base Mérimée: http://www2.culture.gouv.fr/public/mistral/merimee_fr? ACTION=RETROUVER\&FIELD_1=cmer1\&VALUE_1=autun\&FIELD_2=cmer4\&VALUE_2=\&FIELD_3=cmer5\&VALUE_3=\&FIELD_4=AUTR\&VA 16. - Voir dans la base Mérimée: http://www2.culture.gouv.fr/public/mistral/merimee_fr? ACTION=RETROUVER\&FIELD_1=cmer1\&VALUE_1=dijon\&FIELD_2=cmer4\&VALUE_2=\&FIELD_3=cmer5\&VALUE_3=\&FIELD_4=AUTR\&VAL 17. - Voir dans la base Mérimée: http://www2.culture.gouv.fr/public/mistral/merimee_fr? ACTION=RETROUVER\&FIELD_1=cmer1\&VALUE_1=tonnerre\&FIELD_2=cmer4\&VALUE_2=\&FIELD_3=cmer5\&VALUE_3=\&FIELD_4=AUTR\& 18. - Voir BLONDEL, Madeleine. Dijon clair-obscur. Op. cit.

19. - Voir dans la base Mérimée: http://www2.culture.gouv.fr/public/mistral/merimee_fr? ACTION=RETROUVER\&FIELD_1=cmer1\&VALUE_1=nevers\&FIELD_2=cmer4\&VALUE_2=\&FIELD_3=cmer5\&VALUE_3=\&FIELD_4=AUTR\&VA 20. - Voir : http://www2.culture.gouv.fr/public/mistral/merimee_fr.

21. - Voir dans la base Mérimée: http://www2.culture.gouv.fr/public/mistral/merimee_fr? ACTION=RETROUVER\&FIELD_1=cmer1\&VALUE_1=autun\&FIELD_2=cmer4\&VALUE_2=\&FIELD_3=cmer5\&VALUE_3=\&FIELD_4=AUTR\&VA 22. - Voir dans la base Mérimée: http://www2.culture.gouv.fr/public/mistral/merimee_fr? ACTION=RETROUVER\&FIELD_1=cmer1\&VALUE_1=saulieu\&FIELD_2=cmer4\&VALUE_2=\&FIELD_3=cmer5\&VALUE_3=\&FIELD_4=AUTR\&V 23. - Voir dans la base Mérimée: http://www2.culture.gouv.fr/public/mistral/merimee_fr? ACTION=RETROUVER\&FIELD_1=cmer1\&VALUE_1=marsannay\%20la\%20cote\&FIELD_2=cmer4\&VALUE_2=\&FIELD_3=cmer5\&VALUE_3=\& 24. - Pour plus de détails, nous renvoyons à l'article de LOPPINET-MÉO, Sophie. «Le café du Rocher à Marsannay-la-Côte, Côte-d'Or. Un décor du XIX siècle miraculeusement conservé ». Monumental, 2017, $\mathrm{n}^{\circ}$ 2, p. 90.

25. - MERMET, Anne-Cécile et GRAVARI-BARBAS, Maria. «Commerce et patrimoine. L'exemple du Marais à Paris ». Les Annales de la recherche urbaine, 2013, nº 108, p. 56-67. Voir le site : http:// www.annalesdelarechercheurbaine.fr/commerce-et-patrimoine-l-exemple-du-marais-a-parisa667.html [consulté le 17/10/2019].

\section{RÉSUMÉS}

Région gastronomique par excellence, la Bourgogne possède un certain nombre d'édifices liés à cette thématique et protégés au titre des monuments historiques. La conservation régionale des Monuments historiques a conduit depuis près de quarante ans plusieurs campagnes de protection de commerces, halles, cafés et restaurants. Face aux mutations commerciales du $\mathrm{xx}^{\mathrm{e}}$ siècle, ces mesures, classement ou inscription, ont tenté de conserver des devantures ou des aménagements intérieurs, $\mathrm{du}$ tournant des $\mathrm{xIX}^{\mathrm{e}}$ et $\mathrm{xx}^{\mathrm{e}}$ siècles, témoins de leur époque. Ces protections n'ont toutefois pas permis de maintenir les commerces qui ont bien souvent fermé ou été transformés. De même, si elles reconnaissent l'intérêt artistique et historique des lieux, elles n'ont pas été à même, comme le ferait un musée, de préserver la mémoire de ces commerces ou les objets qui pouvaient s'y trouver. L'étude de cette thématique se poursuit toutefois et s'intéresse aux réalisations de la première moitié $\mathrm{du} \mathrm{xx}^{\mathrm{e}}$ siècle.

The Burgundy region is may be seen as a gastronomic region par excellence and today it has a certain number of buildings which are associated with this theme and which are protected under the terms of French legislation on historic monuments. For over forty years now, the region's historic monuments conservation service has carried out several campaigns of statutory protection on shops, market halls, cafés and restaurants. In response to the commercial changes 
witnessed during the late twentieth century, these protective measures-classification or inscription-aimed above all at preserving the shopfronts and interior designs dating from the turn of the nineteenth and twentieth centuries, elements characteristic of their period. But historic monument protection of the tangible heritage has not meant, however, that the original commercial activity has always been maintained, and many of the protected establishments have closed down or been transformed. In the same way, if the protective measures give proper recognition to the artistic and historic interest of the places, they have not made them into museums and have not necessarily preserved the memory of the commercial activity or the objects originally associated with this activity. Nonetheless, the study of this theme continues in the region and is now focusing on places dating from the first half of the twentieth century.

\section{INDEX}

Mots-clés : Bourgogne, gastronomie, monuments historiques, échoppes, boutiques, halles, marchés, cafés, restaurants, devantures, vitrines, boucheries, charcuteries, confiseries

Keywords : Burgundy, gastronomy, historic monuments, market stall, shop, market hall, market, café, restaurant, shopfront, shop window, butcher's shop, charcuterie, sweet shop

\section{AUTEUR}

\section{MICHAËL VOTTERO}

Conservateur régional adjoint des monuments historiques, DRAC Bourgogne-Franche-Comté, Chercheur associé Centre Georges Chevrier, Université de Bourgogne

michael.vottero@culture.gouv.fr 